\title{
Perinatal mortality by gestational week and size at birth in singleton pregnancies at and beyond term: a nationwide population-based cohort study
}

Nils-Halvdan Morken ${ }^{1,2,3^{*}}$, Kari Klungsøyr ${ }^{1,4}$ and Rolv Skjaerven ${ }^{1,4}$

\begin{abstract}
Background: Whether gestational age per se increases perinatal mortality in post-term pregnancy is unclear. We aimed at assessing gestational week specific perinatal mortality in small-for-gestational-age (SGA) and non-SGA term and post-term gestations, and specifically to evaluate whether the relation between post-term gestation and perinatal mortality differed before and after ultrasound was introduced as the standard method of gestational age estimation.

Methods: A population-based cohort study, using data from the Medical Birth Registry of Norway (MBRN), 1967-2006, was designed. Singleton births at 37 through 44 gestational weeks ( $n=1855$ 682), excluding preeclampsia, diabetes and fetal anomalies, were included. Odds ratios (OR) with 95\% confidence intervals (Cl) for perinatal mortality and stillbirth in SGA and non-SGA births by gestational week were calculated.
\end{abstract}

Results: SGA infants judged post-term by LMP had significantly higher perinatal mortality than post-term non-SGA infants at 40 weeks, independent of time period (highest during 1999-2006 [OR 9.8, 95\% Cl: 5.7-17.0]). When comparing years before (1967-1986) versus after (1987-2006) ultrasound was introduced, there was no decrease in the excess mortality for post-term SGA versus non-SGA births (ORs from 6.1 [95\% Cl: 5.2-7.1] to 6.7 [5.2-8.5]), while mortality at 40 weeks decreased significantly (ORs from 4.6, [4.0-5.3] to 3.2 [2.5-3.9]). When assessing stillbirth risk (1999-2006), more than 40\% of SGA stillbirths (11/26) judged to be $\geq 41$ weeks by LMP were shifted to lower gestational ages using ultrasound estimation.

Conclusions: Mortality risk in post-term infants was strongly associated with growth restriction. Such infants may erroneously be judged younger than they are when using ultrasound estimation, so that the routine assessment for fetal wellbeing in the prolonged gestation may be given too late.

Keywords: Perinatal mortality, Stillbirth, Small-for-gestational-age (SGA), Term, Post-term

\section{Background}

Post-term pregnancy is defined by the World Health Organization and the International Federation of Obstetrics and Gynecology as a pregnancy proceeding to and beyond 294 days of gestation i.e. 42 weeks +0 days [1-3]. The term prolonged pregnancy has commonly been used

\footnotetext{
* Correspondence: nils-halvdan.morken@kk.uib.no

'Department of Global Public Health and Primary Care, University of Bergen, Bergen, Norway

${ }^{2}$ Department of Clinical Sciences, University of Bergen, Bergen, Norway Full list of author information is available at the end of the article
}

about pregnancies proceeding to or beyond 287 days of gestation, corresponding to 41 weeks +0 days [4]. Both conditions have been associated with numerous maternal and neonatal adverse outcomes [4-10].

When analyzing implications of post-term pregnancy, the method of gestational age estimation is crucial. It is known that ultrasound based estimation of gestational age gives more precise results than estimation based on menstrual dates [11-15]. However, it is also known that ultrasound based estimation tends to shift the entire gestational age distribution towards younger ages [16],

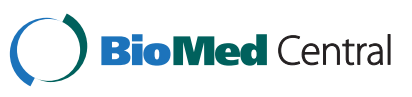


probably due to the standards applied for ultrasound measurements at around 18 weeks (the most common time for estimation of due dates). This leads to a decrease in post-term and an increase in preterm gestations when compared to estimations based on menstrual dates $[16,17]$. This is particularly a problem for infants that are growth restricted, some of which will be growth restricted already at around 18 weeks [18], and thus may be given a "younger" age than they actually have.

Earlier studies on the relation between post-term gestation and perinatal outcome have used last menstrual period (LMP) as basis for gestational age estimation, often because they were done before ultrasound based estimation was an established and well proven standard in clinical practice, or such data were not available [7-9,19-21]. Since ultrasound was introduced in the late 1970s, it quickly replaced last menstrual periods as the standard estimation of gestational age in clinical practice, and thus post-term pregnancies were defined based on ultrasound derived dates.

We hypothesized that death risk in post-term pregnancies is strongly associated with being small-for-gestational age (SGA) and that the implementation of ultrasoundbased estimates of gestational age may have had a negative impact especially for the growth restricted infants being assessed as post-term later than they should. The main purpose of the current study was to assess the risk of perinatal death in SGA and non-SGA term and post-term gestations by gestational week, and specifically to evaluate whether the relation between post-term gestation and perinatal mortality was different in the time period before and after ultrasound was introduced as the standard method of gestational age estimation. We also performed analyses in a subset of the data where gestational age from both ultrasound and menstrual date estimations were registered (1999-2006). In this period, we also assessed stillbirth risk separately, using ongoing pregnancies as the risk population (fetus at risk approach).

\section{Methods}

\section{Data source}

A population-based cohort study was designed using data from the Medical Birth Registry of Norway (MBRN) from 1967 to 2006. The register was established in 1967 by the Directorate of Health and was the first national medical birth registry in the world. It is based on compulsory notification of all live births and stillbirths from 16 weeks (since 2002, from 12 weeks) of gestation. A standardized notification form is used to collect data on demographic variables, maternal health before and during pregnancy, previous reproductive history, complications during pregnancy and delivery and pregnancy outcomes. This notification form was almost unchanged from 1967 until 1999. Beginning in 1999, a new and more detailed form was introduced in which maternal smoking habits and ultrasound based due dates were included. All records in the MBRN are matched with the files of the Central Person Register, to ensure medical notification of every newborn in Norway [22], and to collect dates of deaths.

\section{Study population}

We included singleton pregnancies with gestational ages between 37 weeks +0 days (259 days of gestation) and 43 weeks +6 days (307 days of gestation), thus excluding preterm births. Proportions of misclassified gestational ages were $0.1 \%$ in the term and $0.09 \%$ in the post-term populations (birth weight $>4$ standard deviations above or below their gestational week specific mean). We also excluded pregnancies where mothers were registered with preeclampsia, gestational and pre-gestational diabetes, as well as pregnancies where the delivered infant was registered with congenital anomalies. In data from 1999-2006, we excluded daily smoking mothers from the main analyses. However, to assess the impact of adjusting for maternal smoking habits, we did a separate analysis with smoking mothers included (total $n=269$ 628).

\section{Definitions and statistical analyses}

The following sources are available to estimate gestational age in the MBRN: 1) LMP (registered from 1967) and 2) expected date of parturition according to ultrasound measurements (registered from 1999). Ultrasound based estimation of gestational age was officially introduced to all pregnant women in Norway in 1986 after recommendation from a consensus panel, and very rapidly replaced estimation based on LMPs. The vast majority of obstetric departments in our public health care system (used by nearly all pregnant Norwegian women) used the same standard formula to estimate gestational age by ultrasound during the present study period, based on bi-parietal-diameter (BPD) measurements in the second trimester [23]. When evaluating the implication of the change from menstrual-based to ultrasound-based due dates on the relation between post-term gestation and perinatal mortality, we divided the study period into two: 1967-86 and 1987-2006, and compared the relation between post-term gestation (based on LMP) and perinatal mortality in these two periods. LMP based gestational age was further used for main analyses and time trends, but in a subset of data from 1999-2006 we used ultrasound based gestational age in addition, to compare results using the different gestational age estimations.

We defined post-term pregnancy in accordance with the recommended, standardized and internationally endorsed definition of a pregnancy lasting $\geq 294$ days (42 weeks +0 days) of gestation. In addition we estimated risks per gestational week from 37 to $42+$. 
Perinatal death was defined as stillbirth or death within seven days of life. SGA was defined as infant birth weight by gestational age below the 10th percentile according to a national standard based on data from the MBRN [24]. This criterion is in accordance with common clinical practice [24].

Odds ratios (OR) with 95\% confidence intervals (CI) were obtained using logistic regression analyses (IBM SPSS Statistics 19.0 SPSS Inc, Chicago, Illinois, www.spss. com). Pregnancies were categorized according to completed gestational weeks into six strata from 37 weeks to $\geq 42$ weeks. Within each week, we further categorized births as SGA or non-SGA. Non-SGA at 40 weeks was used as the reference category in all analyses. The following variables were evaluated as possible confounders, and adjusted for in the logistic regression analyses: Parity (nulliparous or multiparous), maternal age $(<20,20-24$, 25-29, 30-34 and 35+ years) and fetal sex. LMP data were analyzed in four separate time periods; 1967-1976, 19771986, 1987-1998 and 1999-2006, where reference groups were non-SGA births at 40 weeks in the specific time period. When analyzing the two periods 1967-1986 versus 1987-2006, we also adjusted for time period using two 10-year groups within each main period, and likewise, when analyzing the total material we used four 10-year periods in the logistic regression analyses. In a separate analysis for the years 1999-2006 we also included maternal smoking habits as a confounder (daily smoking yes/no).

Since our main outcome was gestational week specific perinatal mortality, and approximately $2 / 3$ of perinatal death are stillbirths, we also estimated the risk of stillbirth by gestational week separately, using the fetus at risk approach, where ongoing pregnancies at each week constituted the risk population. In order to compare ultrasound and LMP-based estimation of gestational age, these calculations were done for the period 1999-2006.

The MBRN approved the study and provided the data for this analysis. The study was based on anonymous data and was thus exempt from ethical institutional review board approval according to Norwegian legislation.

\section{Results}

In the total cohort of LMP dated pregnancies during 1967 to 2006 ( $n=1855682), 6308$ perinatal deaths were registered, giving a perinatal mortality risk of $0.34 \%$. For the period 1999 to 2006, where both menstrual and ultrasound based estimation of gestational age was available $(n=234719)$, the risk was $0.18 \%$, (412 perinatal deaths; 77 early neonatal and 335 stillbirths).

\section{LMP-based gestational age 1967-2006}

Gestational age specific perinatal death in non-SGA and SGA infants when using LMP based gestational age is reported in Tables 1 and 2, showing results for the different time periods. Table 3 shows results for the total cohort, 1967-2006. The SGA infants had significantly higher perinatal mortality than the reference group in all gestational weeks, and the perinatal mortality showed an inverse J-pattern with lowest risk at 40 weeks and increasing risks both in the weeks below and above 40 . Using non-SGA infants at 40 weeks as reference in all time periods, the highest OR of perinatal death for postterm gestations was found among SGA infants during 1999-2006 (adjusted OR: 9.8, 95\% CI: 5.7-17.0). The post-term non-SGA infants also had a significantly increased risk of perinatal death, again with the strongest association during 1999-2006: adjusted OR 2.0 (1.4-2.7).

To assess if size at birth (SGA or non-SGA) modified the association between post-term gestational age and perinatal mortality, interaction analyses between SGA status and post-term gestational age were performed. We compared the perinatal mortality risk at 40 and $\geq 42$ weeks gestation in a sub-set of the data during 1987-2006 ( $\mathrm{n}=385$ 277). The $\mathrm{p}$-value for interaction was 0.01 in a multiplicative model. In stratified analyses the OR for perinatal mortality was 3.1 (2.5-4.0) for nonSGA post-term and $4.9(3.8-6.4)$ in SGA post-term infants, using non-SGA infants at 40 weeks as the reference. Adjustments were made for maternal age, parity, fetal sex and time period.

\section{Before versus after ultrasound estimates were introduced}

Figure 1 shows the relation between LMP-based gestational age and adjusted OR of perinatal death for SGA births relative non-SGA births at 40 weeks in two time periods; before (1967-1986) and after (1987-2006) ultrasound was introduced as the standard gestational age estimation method. We see that the increase in excess mortality risk by gestational week from 40 to $42+$ is larger in the last than in the first time period. Further, the excess mortality risk, expressed as OR values, for SGA relative non-SGA births at 40 weeks decreased from the first to the second period (4.6 [4.0-5.3] and 3.2 [2.5-3.9], respectively), whereas at $42+$ weeks there was no significant change (6.1, [5.2-7.1] and 6.7 [ 5.2-8.5], respectively). We found a significant interaction between time period and LMP based post-term gestation for SGA infants when analyzing the relation between postterm SGA gestation and perinatal mortality, using non-SGA infants at 40 weeks as reference $(\mathrm{p}<0.0005$, multiplicative model).

\section{LMP-based gestational age versus ultrasound-based gestational age, 1999-2006}

Table 4 shows ORs of perinatal death by gestational week, SGA status and method of gestational age estimation (LMP and ultrasound) in a sub-set of the total cohort (1999-2006). In this table we only show results 
Table 1 Perinatal mortality for singleton births in Norway 1967-1976 ( $n=531098$ ) and 1977-1986 ( $=416735)$ according to LMP-based gestational age and size at birth (small-for-gestational-age [SGA] and non-SGA)

\begin{tabular}{|c|c|c|c|c|c|c|c|}
\hline \multirow[b]{2}{*}{$\begin{array}{l}\text { Gestational age } \\
\text { in weeks }\end{array}$} & \multicolumn{3}{|c|}{ Non-SGA } & \multicolumn{4}{|c|}{ SGA } \\
\hline & $\begin{array}{l}\text { Perinatal deaths } \\
\mathrm{n} \text { (per 1000) }\end{array}$ & Adjusted $\mathrm{OR}^{\alpha}$ & $95 \% \mathrm{Cl}$ & $\begin{array}{l}\text { Perinatal deaths } \\
\mathrm{n}(\text { per 1000) }\end{array}$ & $\begin{array}{l}\text { SGA\% of deaths } \\
\text { per week }\end{array}$ & Adjusted $\mathrm{OR}^{a}$ & $95 \% \mathrm{Cl}$ \\
\hline \multicolumn{8}{|l|}{ 1967-1976 } \\
\hline 37 & $192(11.4)$ & 4.1 & $3.5-4.9$ & $213(89.0)$ & 52.6 & 35.1 & $29.5-41.7$ \\
\hline 38 & $228(5.6)$ & 2.0 & $1.7-2.4$ & $226(40.7)$ & 49.8 & 15.3 & $13.0-18.1$ \\
\hline 39 & $293(3.1)$ & 1.1 & $0.96-1.3$ & $236(18.3)$ & 44.6 & 6.9 & $5.8-8.1$ \\
\hline 40 & $379(2.7)$ & 1.0 & Reference & $222(11.3)$ & 36.9 & 4.3 & $3.6-5.1$ \\
\hline 41 & $327(3.0)$ & 1.1 & $0.98-1.3$ & $187(12.4)$ & 36.4 & 4.7 & $4.0-5.6$ \\
\hline$\geq 42$ & $316(4.8)$ & 1.8 & $1.6-2.1$ & $150(15.1)$ & 32.2 & 5.8 & $4.8-7.0$ \\
\hline \multicolumn{8}{|l|}{ 1977-1986 } \\
\hline 37 & $94(7.3)$ & 5.4 & $4.2-7.0$ & $103(62.0)$ & 52.3 & 49.0 & $37.9-63.4$ \\
\hline 38 & $110(3.5)$ & 2.6 & $2.0-3.3$ & $78(19.0)$ & 41.5 & 14.4 & $11.0-19.0$ \\
\hline 39 & $155(2.1)$ & 1.5 & $1.2-1.9$ & $87(9.3)$ & 36.0 & 7.1 & $5.4-9.2$ \\
\hline 40 & $147(1.3)$ & 1.0 & Reference & $100(7.4)$ & 40.5 & 5.6 & $4.4-7.3$ \\
\hline 41 & $150(1.7)$ & 1.3 & $1.01-1.6$ & $92(8.8)$ & 38.0 & 6.7 & $5.2-8.8$ \\
\hline$\geq 42$ & $124(2.4)$ & 1.8 & $1.4-2.3$ & $57(8.8)$ & 31.5 & 6.7 & 4.9-9.1 \\
\hline
\end{tabular}

Pregnancies with preeclampsia, pregestational and gestational diabetes and infants with congenital anomalies were excluded.

${ }^{a}$ Adjustments by logistic regression where the following confounders were included: maternal age $(<20,20-24,25-29,30-34$ and $35+)$, parity (para 0, para $\left.1+\right)$ and fetal sex.

from pregnancies where both LMP and ultrasound estimation were registered, therefore, data varies slightly from those analyzed in Table 2. The risk of perinatal death was significantly increased in SGA infants at 41 and $\geq 42$ weeks relative non-SGA infants at 40 weeks, independent of gestational age estimation method. However, the strongest association by far was found for LMP-dated infants at $\geq 42$ weeks (adjusted OR: 10.1, 95\% CI: 5.8-17.6). For non-SGA infants at 41 and $\geq 42$ weeks, only the post-term infants dated by LMP had significantly increased perinatal mortality (adjusted OR: 1.9, 95\% CI: 1.3-2.7).

\section{Maternal smoking}

Maternal smoking is a well-known risk factor for SGA and may also affect gestational age and perinatal mortality. We performed a sub-analysis for the years 19992006, and included smoking habits (daily smoking yes/ no) as a confounder in addition to maternal age, parity and fetal sex, when studying the relation between postterm gestational age and perinatal mortality. When using LMP-based gestational age estimation, the adjusted OR of perinatal death for post-term SGA infants was 8.3 (95\% CI: 5.1-13.6) and for post-term non-SGA infants it was 1.8 (95\% CI: 1.3-2.4); both relative non-SGA infants at 40 weeks. When ultrasound based gestational age was used, the corresponding ORs were 4.5 (95\% CI: 2.0-10.4) and 1.3 (95\% CI: 0.9-1.9).

\section{Stillbirth risk with fetus at risk approach}

We repeated analyses for the last time period (1999 to 2006) with gestational age specific stillbirth risk (SGA and non-SGA pregnancies) as outcomes. We compared results using LMP and ultrasound estimation of gestational age. Results are shown in Table 5 where the ongoing pregnancies at each week are the risk population, and non-SGA pregnancies in each week the reference groups. The post-term SGA infants had six to seven times increased risk of stillbirth when compared to postterm non-SGA infants (OR: 7.0 [3.7-13.3] and 6.3 [2.316.9]) for LMP-based and ultrasound-based gestational age, respectively. When comparing post-term SGA death to 40 weeks non-SGA, ORs for stillbirth were 20.5 (11.337.5) and 13.5 (5.4-33.5) for LMP-based and ultrasoundbased gestational age, respectively. There were too few early neonatal deaths $(n=77)$ to do separate analyses for this group.

The number of SGA stillbirths defined as being 41 and $\geq 42$ was 26 when estimation was based on LMP and only 15 when based on ultrasound. Accordingly, 42.3\% $(11 / 26)$ of the prolonged SGA deaths were shifted to lower gestational ages by using ultrasound estimation.

\section{Discussion}

In this study we found strong and consistent associations over time between prolonged and post-term gestational age and perinatal mortality for SGA infants. Further, post-term SGA infants were at significantly 
Table 2 Perinatal mortality for singleton births in Norway 1987-1998 ( $n=550$ 911) and 1999-2006 ( $n=244009)$ according to LMP-based gestational age and size at birth (small-for-gestational-age [SGA] and non-SGA)

\begin{tabular}{|c|c|c|c|c|c|c|c|}
\hline \multirow[b]{2}{*}{$\begin{array}{l}\text { Gestational age } \\
\text { in weeks }\end{array}$} & \multicolumn{3}{|c|}{ Non-SGA } & \multicolumn{4}{|c|}{ SGA } \\
\hline & $\begin{array}{l}\text { Perinatal deaths } \\
\mathrm{n} \text { (per 1000) }\end{array}$ & Adjusted $O R^{a}$ & $95 \% \mathrm{Cl}$ & $\begin{array}{l}\text { Perinatal deaths } \\
\mathrm{n} \text { (per 1000) }\end{array}$ & $\begin{array}{l}\text { SGA\% of deaths } \\
\text { per week }\end{array}$ & Adjusted $O R^{a}$ & $95 \% \mathrm{Cl}$ \\
\hline \multicolumn{8}{|l|}{ 1987-1998 } \\
\hline 37 & $120(6.1)$ & 4.4 & $3.5-5.5$ & 78 (36.8) & 39.4 & 27.3 & $20.9-35.6$ \\
\hline 38 & $103(2.1)$ & 1.5 & $1.2-1.9$ & $87(16.3)$ & 45.8 & 11.8 & $9.1-15.2$ \\
\hline 39 & $166(1.6)$ & 1.2 & $0.94-1.4$ & $100(8.8)$ & 37.6 & 6.4 & $5.0-8.1$ \\
\hline 40 & $201(1.4)$ & 1.0 & Reference & $67(4.4)$ & 25.0 & 3.2 & $2.4-4.2$ \\
\hline 41 & $157(1.4)$ & 0.99 & $0.8-1.2$ & $49(4.3)$ & 23.8 & 3.1 & $2.3-4.3$ \\
\hline$\geq 42$ & $115(1.7)$ & 1.2 & $0.97-1.5$ & $63(9.3)$ & 35.4 & 6.8 & $5.1-9.1$ \\
\hline \multicolumn{8}{|l|}{ 1999-2006 } \\
\hline 37 & $34(3.7)$ & 3.5 & $2.3-5.3$ & $13(16.6)$ & 27.7 & 15.8 & $8.7-28.7$ \\
\hline 38 & $47(2.0)$ & 1.9 & $1.3-2.8$ & $21(11.5)$ & 30.9 & 10.9 & $6.7-17.9$ \\
\hline 39 & $66(1.4)$ & 1.4 & $0.97-1.9$ & $29(8.8)$ & 30.5 & 8.3 & $5.4-12.9$ \\
\hline 40 & $69(1.0)$ & 1.0 & Reference & $13(3.3)$ & 15.9 & 3.2 & $1.7-5.7$ \\
\hline 41 & $69(1.3)$ & 1.3 & $0.9-1.8$ & $16(5.6)$ & 18.8 & 5.4 & $3.1-9.3$ \\
\hline$\geq 42$ & $63(2.0)$ & 2.0 & $1.4-2.7$ & $16(10.2)$ & 20.3 & 9.8 & $5.7-17.0$ \\
\hline
\end{tabular}

Pregnancies with preeclampsia, pre-gestational and gestational diabetes and infants with congenital anomalies were excluded. For $1999-2006$ smoking mothers were also excluded.

${ }^{a}$ Adjustments by logistic regression where the following confounders were included: maternal age $(<20,20-24,25-29,30-34$ and $35+)$, parity (para 0, para $1+$ ) and fetal sex.

higher mortality risk than post-term non-SGA infants. Of particular importance was that the highest excess risk of perinatal death for SGA infants defined as post-term by LMP was found in the last half of the study period, after ultrasound was introduced as a standard estimation method in clinical practice. Assessing stillbirth risk in the last time period, more than $40 \%$ of SGA stillbirths were shifted from having prolonged gestation to term weeks when based on ultrasound instead of LMP. Also, for deliveries with due dates postponed by ultrasound during (1999-2006), the OR's for perinatal death in prolonged and post-term SGA babies (calculated with risk per week) increased from 4.0 and 5.5 to 5.0 and 8.0, respectively (analyses not shown). Routine assessment of fetal wellbeing in the prolonged and post-term gestations would therefore have been missed in these pregnancies.

Our study thus suggests a possible negative impact of changing gestational age estimation method on the relation between post term gestation and mortality risk. The acknowledged shift [16] in gestational age distribution towards younger gestations when using ultrasound measurements at 18 weeks is mostly a problem for growth restricted infants, some of which may be growth restricted also at this early age [18]. These fetuses will mistakenly be judged as younger than they are, and the pregnancies will thus be set up for post-term evaluation too late. At the same time, these growth restricted infants are the exact infants with the highest mortality risk

Table 3 Perinatal mortality for singleton births in Norway 1967-2006 ( $n=1855$ 682) according to LMP-based gestational age and size at birth (small-for-gestational-age [SGA] and non-SGA)

\begin{tabular}{|c|c|c|c|c|c|c|c|}
\hline \multirow[b]{2}{*}{$\begin{array}{l}\text { Gestational age } \\
\text { in weeks }\end{array}$} & \multicolumn{3}{|c|}{ Non-SGA } & \multicolumn{4}{|c|}{ SGA } \\
\hline & $\begin{array}{l}\text { Perinatal deaths } \\
\mathrm{n} \text { (per 1000) }\end{array}$ & Adjusted $O^{a}$ & $95 \% \mathrm{Cl}$ & $\begin{array}{l}\text { Perinatal deaths } \\
\mathrm{n} \text { (per 1000) }\end{array}$ & $\begin{array}{l}\text { SGA\% of deaths } \\
\text { per week }\end{array}$ & Adjusted $\mathrm{OR}^{a}$ & $95 \% \mathrm{Cl}$ \\
\hline 37 & $460(7.3)$ & 4.2 & $3.8-4.8$ & $418(55.2)$ & 47.6 & 32.5 & $28.8-36.6$ \\
\hline 38 & $520(3.4)$ & 2.0 & $1.8-2.2$ & $424(23.3)$ & 44.9 & 13.3 & $11.9-15.0$ \\
\hline 39 & $719(2.1)$ & 1.2 & $1.1-1.4$ & $472(12.0)$ & 39.6 & 6.7 & $6.0-7.5$ \\
\hline 40 & $846(1.7)$ & 1.0 & Reference & $416(7.6)$ & 33.0 & 4.1 & $3.7-4.6$ \\
\hline 41 & 741 (1.9) & 1.1 & $1.02-1.2$ & $352(8.5)$ & 32.3 & 4.6 & $4.1-5.2$ \\
\hline$\geq 42$ & $648(2.8)$ & 1.7 & $1.5-1.8$ & $292(11.3)$ & 31.1 & 6.1 & $5.3-7.0$ \\
\hline
\end{tabular}

Pregnancies with preeclampsia, pre-gestational and gestational diabetes and infants with congenital anomalies were excluded. 


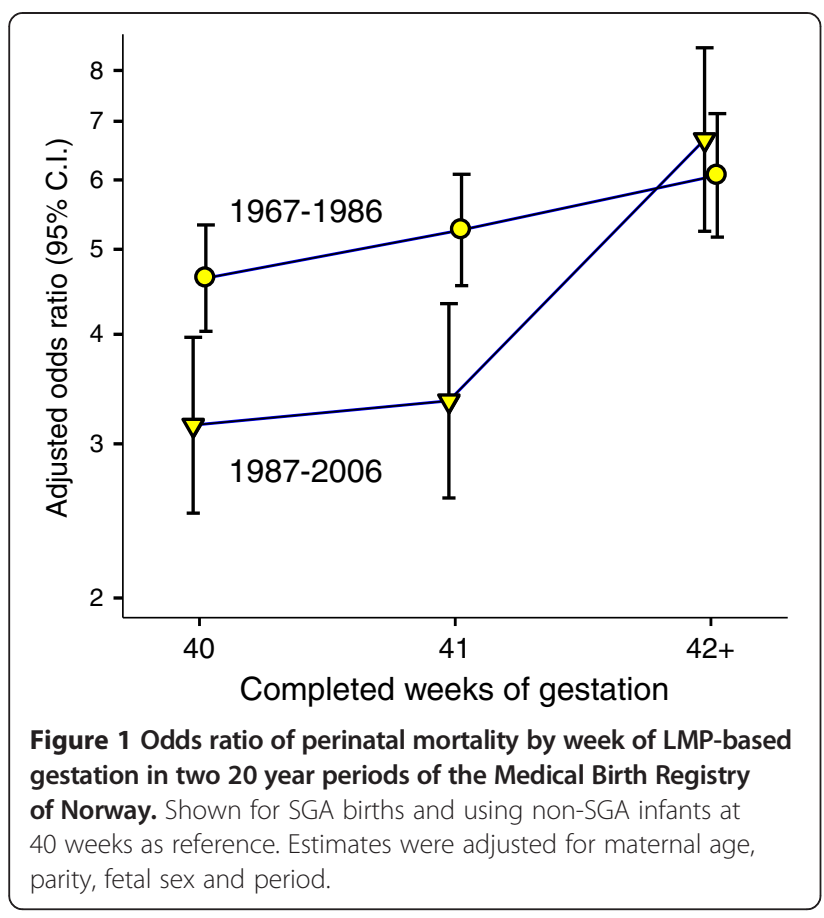

Table 4 Perinatal mortality for singleton births $(n=234719$, of which 412 were perinatal deaths) according to LMP and ultrasound-based gestational age and SGA status in Norway, 1999-2006

\begin{tabular}{|c|c|c|c|c|c|c|}
\hline \multirow[b]{3}{*}{$\begin{array}{l}\text { Gestational age } \\
\text { in weeks }\end{array}$} & \multicolumn{6}{|c|}{ Gestational age by last menstrual period } \\
\hline & \multicolumn{3}{|c|}{ Non-SGA } & \multicolumn{3}{|c|}{ SGA } \\
\hline & $\begin{array}{l}\text { Perinatal deaths } \\
\mathrm{n} \text { (per 1000) }\end{array}$ & $\begin{array}{l}\text { Unadjusted OR } \\
(95 \% \mathrm{Cl})\end{array}$ & $\begin{array}{l}\text { Adjusted } \mathrm{OR}^{\alpha} \\
(95 \% \mathrm{Cl})\end{array}$ & $\begin{array}{l}\text { Perinatal deaths } \\
\mathrm{n} \text { (per 1000) }\end{array}$ & $\begin{array}{l}\text { Unadjusted OR } \\
(95 \% \mathrm{Cl})\end{array}$ & $\begin{array}{l}\text { Adjusted } \mathrm{OR}^{\alpha} \\
(95 \% \mathrm{Cl})\end{array}$ \\
\hline 37 & $18(2.39)$ & $2.3(1.4-3.9)$ & $2.3(1.3-3.8)$ & $9(13.8)$ & $13.5(6.7-27.1)$ & $13.2(6.5-26.6)$ \\
\hline 38 & $42(1.92)$ & $1.9(1.3-2.7)$ & $1.8(1.2-2.7)$ & $17(9.9)$ & $9.6(5.7-16.5)$ & $9.5(5.5-16.2)$ \\
\hline 39 & $63(1.40)$ & $1.3(0.95-1.9)$ & $1.3(0.95-1.9)$ & $28(8.8)$ & $8.5(5.5-13.3)$ & $8.4(5.4-13.1)$ \\
\hline 40 & $67(1.04)$ & 1.0 (Ref.) & 1.0 (Ref.) & $12(3.2)$ & $3.1(1.7-5.7)$ & $3.0(1.6-5.6)$ \\
\hline 41 & $67(1.3)$ & $1.3(0.9-1.8)$ & $1.3(0.9-1.8)$ & $13(4.8)$ & $4.6(2.5-8.3)$ & $4.5(2.5-8.3)$ \\
\hline \multirow[t]{3}{*}{$\geq 42$} & $60(2.0)$ & $1.9(1.3-2.7)$ & $1.9(1.3-2.7)$ & $16(10.5)$ & $10.2(5.9-17.6)$ & $10.1(5.8-17.6)$ \\
\hline & 317 & & & 95 & & \\
\hline & \multicolumn{6}{|c|}{ Gestational age by ultrasound } \\
\hline 37 & $37(4.3)$ & $3.6(2.4-5.3)$ & $3.6(2.4-5.3)$ & $14(22.4)$ & $19.0(10.7-33.6)$ & $18.9(10.6-33.5)$ \\
\hline 38 & $44(1.6)$ & $1.3(0.93-1.9)$ & $1.3(0.92-1.9)$ & $28(14.6)$ & $12.2(7.9-18.8)$ & $12.0(7.8-18.5)$ \\
\hline 39 & $59(1.1)$ & $0.92(0.7-1.3)$ & $0.92(0.7-1.3)$ & $22(5.7)$ & $4.7(3.0-7.6)$ & $4.7(2.9-7.5)$ \\
\hline 40 & $82(1.2)$ & 1.0 (Ref.) & 1.0 (Ref.) & $15(3.6)$ & $3.0(1.7-5.1)$ & $2.9(1.7-5.0)$ \\
\hline 41 & $61(1.3)$ & $1.1(0.8-1.5)$ & $1.1(0.8-1.5)$ & $11(4.9)$ & $4.1(2.2-7.7)$ & $4.0(2.1-7.4)$ \\
\hline \multirow[t]{2}{*}{$\geq 42$} & $34(1.8)$ & $1.5(1.0-2.2)$ & $1.5(0.97-2.2)$ & $5(7.0)$ & $5.8(2.4-14.4)$ & $5.5(2.2-13.7)$ \\
\hline & 317 & & & 95 & & \\
\hline
\end{tabular}

Pregnancies with preeclampsia, pregestational and gestational diabetes, infants with congenital anomalies and smoking mothers were excluded. ${ }^{a}$ Adjustments by logistic regression where the following confounders were included: maternal age $(<20,20-24,25-29,30-34$ and $35+)$, parity (para 0 , para $\left.1+\right)$ and fetal sex. in the post term period. Maternal smoking and fetal sex are among the factors that reduce or affect fetal size in early pregnancy, and have been shown to deflate the risk of post-term delivery when gestational age was based on ultrasound measurements [17]. A recent Swedish study found an increased risk of adverse perinatal outcome among female infants classified as post-term compared with their male counterparts after introduction of ultragestational age estimation may reduce the total burden of post-term delivery by shifting the entire distribution towards younger gestational ages, but the prize seems to be paid by the small, misclassified fetus.

Our findings of an association between post-term gestation and perinatal mortality for SGA infants are in line with earlier studies $[7,19]$. However, we also show an interaction between SGA status and post-term gestation in LMP dated pregnancies with significantly higher excess mortality for SGA than non-SGA post-term infants. This suggests that the perinatal mortality risk in the post-term pregnancy is mostly linked to growth restriction rather than to the prolonged gestational age per se.

We also found a significantly increased risk of perinatal death in non-SGA post-term infants when gestational age was based on menstrual dates, whereas mortality was not significantly increased when post-term gestation was based on ultrasound. In a large Californian sound for estimation of gestational age [25]. Ultrasound 
Table 5 Odds ratio (OR) for stillbirth (335 stillbirths) among 234719 singleton births by size at birth (small-for-gestational-age [SGA] or non-SGA) and method of gestational age estimation, analyzed with fetus at risk approach, Norway, 1999-2006

\begin{tabular}{|c|c|c|c|c|c|c|c|c|}
\hline \multicolumn{8}{|c|}{ Gestational age by last menstrual period } & \multirow{3}{*}{$\begin{array}{l}\text { Stillbirths } \\
\text { n (\%) }\end{array}$} \\
\hline \multirow[b]{2}{*}{$\begin{array}{l}\text { Gestational } \\
\text { age in weeks }\end{array}$} & \multicolumn{3}{|c|}{ Non-SGA } & \multicolumn{4}{|c|}{ SGA } & \\
\hline & $\begin{array}{c}\text { Stillbirths } \\
\mathrm{n}(\%)\end{array}$ & $\begin{array}{c}\text { Ongoing } \\
\text { pregnancies (n) }\end{array}$ & $\begin{array}{c}\text { Stillbirths per } \\
1000\end{array}$ & $\begin{array}{c}\text { Stillbirths } \\
\mathrm{n}(\%)\end{array}$ & $\begin{array}{c}\text { Ongoing } \\
\text { pregnancies }(n)\end{array}$ & $\begin{array}{c}\text { Stillbirths Per } \\
1000\end{array}$ & $\begin{array}{c}\text { Adjusted }^{\alpha} \text { OR } \\
(95 \% \mathrm{Cl})\end{array}$ & \\
\hline 37 & $15(6.0)$ & 221151 & 0.07 & $8(9.6)$ & 13568 & 0.59 & $7.4(3.1-17.7)$ & $23(6.9)$ \\
\hline 38 & $37(14.7)$ & 213617 & 0.17 & $15(18.1)$ & 12917 & 1.16 & $7.7(4.1-13.8)$ & $52(15.5)$ \\
\hline 39 & $49(19.5)$ & 191764 & 0.26 & $24(28.9)$ & 11207 & 2.14 & $8.6(5.2-14.1)$ & $73(21.8)$ \\
\hline 40 & $61(24.2)$ & 146679 & 0.42 & $10(12.0)$ & 8029 & 1.25 & $3.1(1.6-6.0)$ & $71(21.2)$ \\
\hline 41 & $52(20.6)$ & 82300 & 0.63 & $13(15.7)$ & 4258 & 3.05 & $4.8(2.6-8.9)$ & $65(19.4)$ \\
\hline$\geq 42$ & $38(15.1)$ & 30689 & 1.24 & $13(15.7)$ & 1522 & 8.54 & $7.0(3.7-13.3)$ & $51(15.2)$ \\
\hline Total & $252(100)$ & - & - & $83(100)$ & - & - & - & $335(100)$ \\
\hline \multicolumn{8}{|c|}{ Gestational age by ultrasound } & \\
\hline 37 & $31(12.3)$ & 221151 & 0.14 & $11(13.2)$ & 13568 & 0.81 & $6.1(3.0-12.2)$ & $42(12.5)$ \\
\hline 38 & $38(15.0)$ & 212557 & 0.18 & $25(30.1)$ & 12944 & 1.93 & $11.3(6.7-18.8)$ & $63(18.8)$ \\
\hline 39 & $48(19.1)$ & 185384 & 0.26 & $19(22.9)$ & 11019 & 1.72 & $6.8(4.0-11.7)$ & $67(20.0)$ \\
\hline 40 & $69(27.4)$ & 132559 & 0.52 & $13(15.7)$ & 7156 & 1.82 & $3.7(2.0-6.7)$ & $82(24.5)$ \\
\hline 41 & $44(17.5)$ & 64786 & 0.68 & $10(12.1)$ & 2956 & 3.38 & $4.7(2.3-9.3)$ & $54(16.1)$ \\
\hline$\geq 42$ & $22(8.7)$ & 18779 & 1.17 & $5(6.0)$ & 714 & 7.00 & $6.3(2.3-16.9)$ & $27(8.1)$ \\
\hline Total & $252(100)$ & - & - & $83(100)$ & - & - & - & 335 (100) \\
\hline
\end{tabular}

Pregnancies with preeclampsia, pregestational and gestational diabetes, infants with congenital anomalies and smoking mothers were excluded. ${ }^{a}$ Non-SGA in the same week was the reference category. Adjustments by logistic regression where the following confounders were included: maternal age $(<20,20-24,25-29,30-34$ and $35+)$, parity (para 0 , para $1+)$ and fetal sex. Adjustments only marginally altered the risk estimates.

dataset, Bruckner and colleagues found an increased risk of neonatal mortality in normal-weight prolonged and post-term pregnancies, based on menstrual dates [26]. In the same paper, the authors also expressed the need for more precise estimation of gestational age in these kinds of assessments, and suggested ultrasound estimation [26]. Our results suggest that ultrasound estimation is not uncomplicated, at least when measurements are taken at 18 weeks.

\section{Strengths and limitations}

The most important strength of our study is the large sample size that enabled us to study a rare perinatal outcome by gestational weeks and SGA status. Perinatal death is impossible to study in small scale settings and large datasets are needed, such as that provided by the MBRN.

In this national population-based cohort, selection bias was minimal, as it was based on mandatory reporting of a standardised dataset over a period of 40 years. In a subset of the data we were also able to assess the same set of gestational age specific deaths using two different methods of gestational age estimation at a time when ultrasound was well established, contrary to many other publications on the issue [7-9,19-21].

Information on maternal smoking habits was available from 1999. In a sub analysis for the years 1999-2006 we found that adjusting for smoking habits in addition to maternal age, parity and fetal sex, gave somewhat weaker associations between post-term gestational age and perinatal mortality. However, associations were only marginally affected.

Other studies on the present topic have often merged non-SGA gestations at 37 to 41 weeks into one reference category $[19,21]$. Our results clearly show that perinatal mortality varies considerably within these five weeks. Due to the large data set, we could use non-SGA infants at 40 weeks as the reference category, which reveals an inverse J-shaped mortality curve even within the term weeks.

\section{Clinical implications}

There has been a debate about the handling of prolonged and post-term pregnancies. The decisions regarding routine induction versus expectant management depends on balancing the effects and acceptability of induction against the effectiveness of intensified fetal surveillance in preventing fetal and infant loss [27]. Inducing delivery before the post-term period is advocated [20,28-30], others suggest that these pregnancies could be managed by intensive fetal surveillance. There is no conclusive evidence that routine induction before 42 gestational weeks improve fetal, maternal or neonatal outcomes compared to expectant management [31,32]. 
Selective induction is needed only in cases at increased risk while uncomplicated post-term pregnancies are allowed to proceed until spontaneous onset of delivery or induction within the next week. Our data emphasize the importance of identifying the growth-restricted infants in the prolonged and post-term phase of pregnancy due to their increased perinatal mortality risk. However, one of the most important clinical implications of our study is that these growth restricted infants should probably not have their gestational age determined solely by ultrasound.

\section{Conclusions}

Perinatal death risk in prolonged and post-term pregnancies was strongly associated with SGA, independent of time period and method of gestational age estimation. However, the excess mortality risk seen for SGA infants judged to be post-term by LMP has increased after ultrasound estimation has become routine, when compared to non-SGA infants at 40 weeks. This indicates that pregnancies with growth restricted infants may be judged younger than they are when gestational age is estimated by ultrasound. This was further supported by finding that more than $40 \%$ of SGA stillbirths judged to be $\geq 41$ weeks by LMP were shifted to lower gestational ages when using ultrasound estimation. Routine assessment of fetal wellbeing in the prolonged and post-term gestations will be missed in these pregnancies.

\section{Abbreviations \\ SGA: Small-for-gestational-age; MBRN: Medical Birth Registry of Norway; OR: Odds ratio; LMP: Last menstrual period; Cl: Confidence interval.}

\section{Competing interests}

The authors declare that they have no competing interests.

\section{Authors' contributions}

The investigators of this study had full access to all of the data in the study and take responsibility for the integrity of the data and the accuracy of the data analysis. NHM designed the study, performed the analyses of data and was responsible for interpretation of data analysis and completion of the manuscript. KK contributed in interpretation of data analysis and in the completion of the manuscript. RS designed the study, performed analyses, interpreted data, contributed in completion of the manuscript and is guarantor. All authors read and approved the final manuscript.

\section{Acknowledgements}

The Norwegian Extra-Foundation for Health and Rehabilitation through EXTRA funds and The Unger-Vetlesen Medical Fund are acknowledged.

\section{Funding}

NHM was funded with scholarships by the Norwegian Extra-Foundation for Health and Rehabilitation through EXTRA funds, The University of Bergen and The Unger-Vetlesen Medical Fund. The funding organisations had no influence on planning or performing of the project, interpretation of data or preparation of the manuscript.

\section{Author details}

${ }^{1}$ Department of Global Public Health and Primary Care, University of Bergen, Bergen, Norway. ${ }^{2}$ Department of Clinical Sciences, University of Bergen, Bergen, Norway. ${ }^{3}$ Department of Obstetrics and Gynecology, Haukeland University Hospital, Bergen, Norway. ${ }^{4}$ Medical Birth Registry of Norway, Norwegian Institute of Public Health, Bergen, Norway.
Received: 20 January 2014 Accepted: 7 May 2014

Published: 22 May 2014

\section{References}

1. World Health Organisation: The Prevention of Perinatal Mortality and Morbidity. Geneva, Switzerland: WHO Technical Report Series; Report 457; 1970.

2. FIGO: Report of the FIGO Subcommittee on Perinatal Epidemiology and Health Statistics. London: FIGO; 1986.

3. Heimstad R: Post-term Pregnancy. Trondheim: Norwegian University of Science and Technology; 2007.

4. Caughey AB, Stotland NE, Washington AE, Escobar GJ: Who is at risk for prolonged and postterm pregnancy? Am J Obstet Gynecol 2009, 200(6):683-e681-685.

5. Caughey AB, Bishop JT: Maternal complications of pregnancy increase beyond 40 weeks of gestation in low-risk women. J Perinatol 2006, 26(9):540-545.

6. Caughey AB, Musci TJ: Complications of term pregnancies beyond 37 weeks of gestation. Obstet Gynecol 2004, 103(1):57-62.

7. Divon MY, Haglund B, Nisell H, Otterblad PO, Westgren M: Fetal and neonatal mortality in the postterm pregnancy: the impact of gestational age and fetal growth restriction. Am J Obstet Gynecol 1998, 178(4):726-731.

8. Ingemarsson I, Kallen K: Stillbirths and rate of neonatal deaths in 76,761 postterm pregnancies in Sweden, 1982-1991: a register study. Acta Obstet Gynecol Scand 1997, 76(7):658-662.

9. Olesen AW, Westergaard JG, Olsen J: Perinatal and maternal complications related to postterm delivery: a national register-based study, 1978-1993. Am J Obstet Gynecol 2003, 189(1):222-227.

10. Moster D, Wilcox AJ, Vollset SE, Markestad T, Lie RT: Cerebral palsy among term and postterm births. JAMA 2010, 304(9):976-982.

11. Campbell S, Warsof SL, Little D, Cooper DJ: Routine ultrasound screening for the prediction of gestational age. Obstet Gynecol 1985, 65(5):613-620.

12. Mongelli $M$, Wilcox M, Gardosi J: Estimating the date of confinement: ultrasonographic biometry versus certain menstrual dates. Am J Obstet Gynecol 1996, 174(1 Pt 1):278-281.

13. Tunon K, Eik-Nes SH, Grottum P: A comparison between ultrasound and a reliable last menstrual period as predictors of the day of delivery in 15,000 examinations. Ultrasound Obstet Gynecol 1996, 8(3):178-185.

14. Waldenstrom U, Axelsson O, Nilsson S: A comparison of the ability of a sonographically measured biparietal diameter and the last menstrual period to predict the spontaneous onset of labor. Obstet Gynecol 1990, 76(3 Pt 1):336-338.

15. Wennerholm UB, Bergh C, Hagberg H, Sultan B, Wennergren M: Gestational age in pregnancies after in vitro fertilization: comparison between ultrasound measurement and actual age. Ultrasound Obstet Gynecol 1998, 12(3):170-174.

16. Yang H, Kramer MS, Platt RW, Blondel B, Breart G, Morin I, Wilkins R, Usher R: How does early ultrasound scan estimation of gestational age lead to higher rates of preterm birth? Am J Obstet Gynecol 2002, 186(3):433-437.

17. Henriksen TB, Wilcox AJ, Hedegaard M, Secher NJ: Bias in studies of preterm and postterm delivery due to ultrasound assessment of gestational age. Epidemiology 1995, 6(5):533-537.

18. Smith GC, Smith MF, McNay MB, Fleming JE: First-trimester growth and the risk of low birth weight. N Engl J Med 1998, 339(25):1817-1822.

19. Campbell MK, Ostbye T, Irgens LM: Post-term birth: risk factors and outcomes in a 10-year cohort of Norwegian births. Obstet Gynecol 1997, 89(4):543-548.

20. Caughey AB, Snegovskikh W, Norwitz ER: Postterm pregnancy: how can we improve outcomes? Obstet Gynecol Surv 2008, 63(11):715-724.

21. Clausson B, Cnattingius S, Axelsson O: Outcomes of post-term births: the role of fetal growth restriction and malformations. Obstet Gynecol 1999, 94(5 Pt 1):758-762.

22. Irgens LM: The Medical Birth Registry of Norway. Epidemiological research and surveillance throughout 30 years. Acta Obstet Gynecol Scand 2000, 79(6):435-439.

23. Eik-Nes SH, Grøttum P: Graviditetskalenderen Snurra. Drammen: Scan-Med A/S; 1983.

24. Skjaerven $R$, Gjessing HK, Bakketeig LS: Birthweight by gestational age in Norway. Acta Obstet Gynecol Scand 2000, 79(6):440-449.

25. Skalkidou A, Kieler H, Stephansson O, Roos N, Cnattingius S, Haglund B: Ultrasound pregnancy dating leads to biased perinatal morbidity and neonatal mortality among post-term-born girls. Epidemiology 2010, 21(6):791-796 
26. Bruckner TA, Cheng YW, Caughey AB: Increased neonatal mortality among normal-weight births beyond 41 weeks of gestation in California. Am J Obstet Gynecol 2008, 199(4):421-e421-427.

27. Hilder L, Costeloe K, Thilaganathan B: Prolonged pregnancy: evaluating gestation-specific risks of fetal and infant mortality. Br J Obstet Gynaecol 1998, 105(2):169-173.

28. Doherty L, Norwitz ER: Prolonged pregnancy: when should we intervene? Curr Opin Obstet Gynecol 2008, 20(6):519-527.

29. Hovi M, Raatikainen K, Heiskanen N, Heinonen S: Obstetric outcome in post-term pregnancies: time for reappraisal in clinical management. Acta Obstet Gynecol Scand 2006, 85(7):805-809.

30. Treger M, Hallak M, Silberstein T, Friger M, Katz M, Mazor M: Post-term pregnancy: should induction of labor be considered before 42 weeks? J Matern Fetal Neonatal Med 2002, 11(1):50-53.

31. Mandruzzato G, Alfirevic Z, Chervenak F, Gruenebaum A, Heimstad R, Heinonen S, Levene M, Salvesen K, Saugstad O, Skupski D, Thilaganathan B, World Association of Perinatal Medicine: Guidelines for the management of postterm pregnancy. J Perinat Med 2010, 38(2):111-119.

32. Wennerholm UB, Hagberg H, Brorsson B, Bergh C: Induction of labor versus expectant management for post-date pregnancy: is there sufficient evidence for a change in clinical practice? Acta Obstet Gynecol Scand 2009, 88(1):6-17.

doi:10.1186/1471-2393-14-172

Cite this article as: Morken et al:: Perinatal mortality by gestational week and size at birth in singleton pregnancies at and beyond term: a

nationwide population-based cohort study. BMC Pregnancy and Childbirth 2014 14:172.

\section{Submit your next manuscript to BioMed Central and take full advantage of:}

- Convenient online submission

- Thorough peer review

- No space constraints or color figure charges

- Immediate publication on acceptance

- Inclusion in PubMed, CAS, Scopus and Google Scholar

- Research which is freely available for redistribution 